\title{
15 \\ The Stony Metaphysical Heart of Animalism
}

\author{
David Shoemaker
}

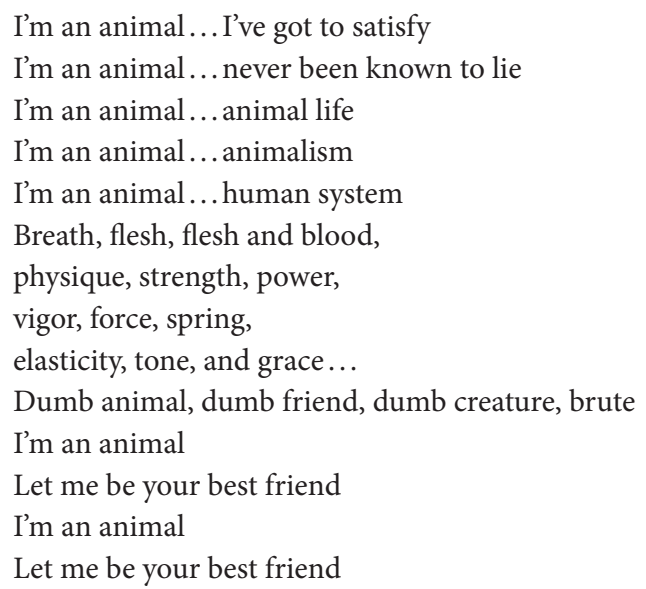

The Animals, "I'm an Animal"

I am not an animal! I am a human being! I am a man!

John Merrick, in David Lynch's The Elephant Man

\begin{abstract}
Animalism, by the forthright acknowledgment of many of its own adherents, does poorly at accounting for our identity-related practical concerns. The reason is straightforward: whereas our practical concerns seem to track the identity of psychological creatures-persons-animalism focuses on the identity of human organisms who are not essentially persons. This lack of fit between our practical concerns and animalism may thus be taken to pose the following serious Challenge to animalism: (1) animalism lacks the proper fit with the set of our practical concerns; (2) if a theory of personal identity lacks the proper fit with the set of our practical concerns, it suffers a loss in
\end{abstract}


plausibility; thus, (3) animalism suffers a loss in plausibility (in particular to psychological criteria of identity).

There are two very general replies to Challenge. First, one might deny (1), showing that animalism doesn't in fact lack the proper fit with our practical concerns. One might tack this response in one of two directions: either (a) appeal to the fact that animal continuity is at least a necessary condition for instantiation of the relevant (psychologically grounded) practical concerns (and so is sufficient for delivering a "proper fit"), or (b) show that our understanding of the relevant practical concerns is overly narrow and that our person-related practical concerns may actually define the "persons" to whom they apply in much broader-humanesque-terms, such that the theory of identity that fits best with them in the end is actually, surprisingly, animalism. The second general response to Challenge is to deny (2), showing instead how a lack of fit with our practical concerns is not a plausibility condition for theories of personal identity.

What we have, then, are actually three attempted responses to Challenge, and these may be drawn from the work of, respectively, David DeGrazia, Marya Schechtman, and Eric Olson. It is my first aim in this chapter to explain and evaluate them. I will find the first two responses problematic and the third, while on the right track, to be significantly incomplete. I will then attempt to fill in the gaps of the third response to render it viable. In doing so, I will show that and how our practical concerns do not consist in a monolithic set; rather, there are distinctly different types of practical concerns, and while some are clearly grounded on psychological relations, some are actually grounded on others, including animalistic and humanistic relations; furthermore, their actual connection to identity is tenuous at best. What these concerns are, how they divide up, and what they are grounded on in each instance-these are the issues it is my second aim in this chapter to take up. I begin with a more thorough explication of Challenge.

\section{Challenge}

Consider the following awful short story, The Party: ${ }^{1}$

As I lie awake in bed this morning and think about how embarrassingly drunk I was when I got into bed last night, I start again to anticipate tonight's party, as many of my old friends will be there (I hope we will recognize one another!). I know that everyone else will be concerned about what they look like, but I am especially concerned about what $I$ will look like: which ascot should I wear? I am also worried about what I will say to the host. She owes me money for some improvisational bricklaying I did at her house last week, and so she had better pay me soon.... When I arrive at the party that evening, I wind up speaking too harshly to the host about what she owes me, and her lummox of a boyfriend confronts me, so I overreact and

${ }^{1}$ From my never-to-be-forthcoming collection of very short stories, Teatime for Troglodytes, and Other Tales. 
punch him in the spleen. She blames me for this rude display and kicks me out of the party. I did not get a chance to catch up with my old friends. It is hot, and I am sad.

Contained in this dreadful display of writing are the essential identity-related practical concerns to which various theorists point: anticipation, first-person recognition and concern, third-person recognition and concern, general social treatment, emotional patterns (e.g. embarrassment), compensation, and responsibility. ${ }^{2}$ These are the concerns that are ostensibly grounded by personal identity: I can justifiably anticipate only my own future experiences; I justifiably have a special sort of concern only for my own future self; I can be justifiably embarrassed, regretful, or proud of only my own past actions or attitudes; I can justifiably be compensated with benefits only for my own burdens; I can justifiably be responsible only for my own past actions; and I am justified in responding to others I claim to recognize in certain ways only if they are the same people I believe them to be.

Taken as a set, these concerns have struck most theorists as being about psychological relations. To take just two examples from the list, anticipation consists in current projective imagination into someone's future experiential states, and responsibility ties some current psychological/moral agent (the target of praise or blame, say) to some past psychological/moral agent (the doer of the deed). The presumed link to identity then goes as follows: if I can justifiably anticipate only my own future experiences and I am responsible only for my own past actions (etc.), and if what makes those experiences or actions my own is that I am numerically identical to the future or past entity to which they are attributable, then if the ownership relation is a psychological relation, so too is the numerical identity relation providing it.

Thus do we arrive at Challenge. If animalism is true, goes the worry, there is a missing link between the ownership of actions/experiences and identity. According to animalism, what makes $\mathrm{X}$ (a person) identical to any individual $\mathrm{Y}$ at any other time is that $\mathrm{X}$ and $\mathrm{Y}$ are one and the same biological organism, one and the same human animal (a sameness typically consisting in biological continuity). ${ }^{3}$ But anticipation (say) is a relation between two experiencers, and so there seems a crucial gap between animalism and the ownership of those experiences, for the animalist would have us saying that what makes the experiences I anticipate mine is ultimately that the experiencer to whom they are attributable will be biologically continuous with me. But what could biological continuity alone have to do with the experiential-psychological-relation that obtains between us? How could the continuity of meat serve to explain a relation of minds?

Surely, goes the objection, if the ownership relation is psychological, then so is its grounding numerical identity relation. That is to say, whatever makes some experience or action mine must be just what renders me identical to that experiencer or agent.

\footnotetext{
2 Compiled from DeGrazia 2005; Locke 1975; Martin 1998; Olson 1997: esp. ch. 3; Schechtman 1996; and Shoemaker 2007.

${ }^{3}$ See, e.g., Olson 1997; and DeGrazia 2005.
} 
Consequently, if what justifies my anticipation of some future experience is that that experience is mine, and it is mine in virtue of my bearing some psychological relation to that experiencer, then that psychological relation is just what makes him me. The fundamental assumption driving Challenge, then, is that the plausibility of a criterion of identity depends, at least in part, on how tightly that criterion is tied to the ownership of actions and experiences relevant to our practical concerns. This assumption thus yields the result that, if animalism falls prey to Challenge, psychological criteria of identity are thereby favored in the plausibility race.

I have already laid out the two general animalist replies to Challenge: either deny that animalism in fact does poorly at linking the ownership of our practical concerns to identity, or deny that such a link is necessary. Turn now to a consideration of the first, which comes in two forms.

\section{Accounting for our Practical Concerns, 1.0: DeGrazia's Realism}

DeGrazia 2005 offers a defense of animalism against a variety of attacks. ${ }^{4}$ One of the more pressing is that animalism cannot account for our practical concerns. DeGrazia's key response is that, in the world as we know it, animalism can indeed account for our practical concerns, at least in virtue of being their necessary condition. He deals explicitly with some of the concerns mentioned earlier-responsibility, prudential concern, and social treatment - as well as more loosely related concerns such as self-knowledge, interest in the afterlife, and what matters in survival. With the exception of our interest in the afterlife, ${ }^{5}$ animalism does rather well as long as we scale back our expectations for success. Consider, for example, moral responsibility, which, again, seems to be grounded on psychological continuity. DeGrazia points out that, in our world-the real world-psychological continuity itself depends on biological continuity: you need continuity of your biological life to support continuity of your psychological

\footnotetext{
${ }^{4}$ See DeGrazia 2005: ch. 2.

${ }_{5}$ This is a very odd concern to include on the list anyway, for it functions quite differently from the others. Take responsibility, for instance. Here, "both ends" of the concern are in place, as it were: we've got someone before us whom we hold responsible for the actions of some past person. Both persons exist, and we are just trying to figure out what metaphysical relations obtain between them that will justify our responsibility-concern. Or consider self-concern: on the assumption that there will exist a person exactly like me getting out of my bed tomorrow, my concern for my well-being extends to him, so what metaphysical relation grounds it? In these cases, then, we stipulate the existence of two person-stages and then explore the metaphysical relation between them, given the antecedent concern that obtains. Our interest in the afterlife, though, functions very differently. Here, we have hopes about the possibility of our surviving the deaths of our bodies. So we aren't-indeed we can't be-stipulating the existence of some heavenly person-stage for whom we already have concern and then trying to figure out the relevant metaphysical grounding relationship. Instead, we simply have a prudential interest in there existing some such heavenly person-stage who is us, but this interest isn't built on any metaphysical relation at all. To hope for the mere obtaining of some metaphysical relation, therefore, is just not to have the sort of concern that is relevant to the type of interaction between our practical concerns and identity that is at issue here. Thanks to Shaun Nichols for discussion of this issue.
} 
life (DeGrazia 2005: 60-1). And similar replies attach to the other concerns. With respect to prudential concern and planning, biological continuity is necessary for them as well in the world as we know it. Furthermore, we may plan or have prudential concern for our future comatose selves, something a story about psychological continuity cannot account for very well while animalism can. And with respect to social treatment, while it's true that people often treat one another as ongoing psychological beings, it's also true that we typically reidentify one another via our bodies, and, further, our socializing extends beyond psychological persons to newborns and those in demented states (DeGrazia 2005: 60).

There is one last, more subtle, response here. We may allow that a psychological continuity theory does better at accounting for our practical concerns without inferring that animalism cannot account for those concerns thereby. And accounting for them as it does is nothing to sneeze at. As DeGrazia puts it with respect to what matters in survival, "[T] he practical concerns under discussion all presuppose or depend on our continued existence; so does what matters in survival, even if we agree that what most matters in survival is psychological continuity or the continuing capacity for consciousness" (DeGrazia 2005: 63, emphasis mine).

There are two general responses here, then: animalism accounts for our practical concerns (a) by providing (at least) their necessary condition in the world as we know it, and (b) this provision is sufficient to stave off Challenge, i.e. sufficient to prevent a decrease in the plausibility of animalism. Sure enough, it is possible that, with various forms of radical technological advances, we will be able to engage in the kind of activities (e.g. fission) wherein animalistic identity could diverge from our practical concerns, but these are "presently hypothetical cases," and that such diverging might occur in this remote future "is an acceptable price to pay for a theory that otherwise seems more coherent, more metaphysically plausible, and more consonant with educated common sense than its competitors" (DeGrazia 2005: 64).

Whether or not these responses are successful depends entirely on what it means for some theory of numerical identity to "account" for our practical concerns. This is a difficult issue, one that DeGrazia sometimes seems to want to sidestep entirely. ${ }^{6}$ But the account he has nevertheless offered doesn't actually give us what we want. I suggest that what the advocates of Challenge are looking for when investigating the alleged relation between numerical identity and our practical concerns is a robust, informative explanation of the justificatory role played by numerical identity qua necessary condition for our practical concerns. To see what I mean, consider moral responsibility (MR). There is a platitude at work here, evident from my earlier discussion of Challenge: I can be morally responsible only for my own actions. ${ }^{7}$ So insofar as the nature of ownership here is presumably cashed out in terms of numerical identity (i.e. what

\footnotetext{
${ }^{6}$ As he puts it, "The biological view is a theory of human identity..., a metaphysical and conceptual theory. Strictly speaking, then, it is not responsible for tracking all of the concerns we tend to associate with identity" (DeGrazia 2005: 63).

${ }^{7}$ See Shoemaker 2011a.
} 
makes some past action my own is just that I am numerically identical to the person who performed it), such identity is a necessary condition in the justification of attributions of MR: you are justified in judging or holding me morally responsible for A only if I am numerically identical to the person who performed A. What the Challengers are looking for, then-beyond precisely what numerical identity itself consists in-is an informative explanation for why numerical identity plays this justifying role. Indeed, this is the respect in which various proposed criteria of identity may be thought to fall short: if the role they would play in justifying attributions of responsibility failed to illuminate those attributions in any real way, they would fail to be relevant to the practical concern in the way many have thought identity to be.

It is with respect to this desideratum that DeGrazia's "account" falls short, for he fails to provide on behalf of animalism any sort of illuminating explanation of its justificatory role with respect to our practical concerns. Consider again the way many view MR: ostensibly, I am morally responsible for A only if I am identical to the individual who performed A. Now if this is our starting point, then we have already assumed that the relation between identity and MR consists in the former being a necessary condition of the latter. Consequently, to propose, as DeGrazia does, that animalism could account for MR by being a necessary condition for it is just to reaffirm that starting point. But animalism had better be a necessary condition for MR, for that is just what the relation between them has to consist in (given our starting assumption). Now perhaps it might be thought that animalism's ability to serve as a necessary condition for MR at least gives us some (as opposed to no) kind of relation to MR, albeit not as robust a relation as we might have liked given that it doesn't deliver a sufficient condition. But no one could plausibly think identity could ever be a sufficient condition for MR anyway-there are surely epistemic and control conditions one must meet in addition to identity-so identity can serve as no more and no less than a necessary condition for MR. DeGrazia's response (a) is, therefore, redundant.

It is also unilluminating. On the methodology I have outlined, to test the plausibility of animalism with respect to MR, we are supposed to plug its criterion of numerical identity into the platitude as an explication of the nature of my ownership of some past action. So on the proposed view, I am morally responsible for A only if I am biologically continuous with the individual who performed $\mathrm{A}$, and you are justified in judging or holding me responsible for A only if I am biologically continuous with that individual. Let us then ask the fundamental question of the enterprise: what explains how biological continuity plays this justifying role in MR? And to this question the only reply is that it supports or enables the psychological continuity that is actually relevant to MR in the world as we know it. But consider the primary constitutive elements of animal persistence: continuity of a functioning brain and brain stem, continuity of a functioning heart, the intake of nutrition, continuous blood circulation, and regular ventilation. Each of these is individually necessary for real-world psychological continuity, but none of them is relevant to an explanation of the justifying relation from identity to $\mathrm{MR}$, and that is because none of them is relevant to explaining what makes 
some past action my own. What makes that action mine must have something to do with the relation between a past agent's volitional network and my own: the desires, beliefs, and intentions that produced that action must bear some sort of relation to my current desires, beliefs, and intentions. ${ }^{8}$ But these are entirely psychological relations. So while there may be multiple non-psychological relations that support or enable these psychological relations, they are simply not the relevant types of necessary condition to play the justificatory role in attributions of MR presumed by the Challengers.

This is precisely why we would get divergence in hypothetical worlds in which fission and other technological marvels occur, where psychological continuity could be prized apart from biological continuity. In such worlds we would presumably still have a robust explanation of how psychological continuity justifies attributions of MR even in the absence of biological continuity. That biological continuity could drop out of the picture with no loss in explanatory value, however, suggests that, even in the world as we know it, biological continuity is not what's doing the explanatory work. So while it may indeed be a necessary condition for MR in our world, it fails to offer the right kind of necessary condition to be explanatorily relevant for our investigation into the relation between identity and the practical concerns. If this is a story that is broadly applicable to the remainder of our practical concerns, then DeGrazia's point (b) remains in doubt as well: the plausibility of animalism could still be downgraded by its ineffectiveness in providing the right kind of grounding relation to those concerns.

\section{Accounting for our Practical Concerns, 2.0: Schechtman's Expanded Persons}

In a recent article and book, Marya Schechtman offers what might be construed as a different way to show how animalism could account for all our practical concerns, a way providing a more plausible route to rescuing the theory from Challenge (Schechtman 2010 and 2014; although she doesn't pitch it in these terms and may, as we will see, ultimately reject it being put in these terms!). Her story begins with what she diagnoses as a fundamental problem for both psychological and biological theories of numerical identity with respect to their alleged bearing on our practical concerns: they both rely too heavily on a Lockean conception of robust personhood. On Locke's view, a person is an intelligent, self-conscious and self-reflective being, one that thus requires some rather sophisticated psychological capacities. These are the capacities, Locke thinks, that ground personhood's "forensic" nature: "person" is a thoroughly normative concept serving as an umbrella term for those creatures that, due to their sophisticated psychological capacities, are both prudentially concerned and morally responsible. Tracking these prudential and moral creatures across time is a matter of tracking the

\footnotetext{
${ }^{8}$ As astute readers may have noticed, why psychological continuity explains this relation any better than biological continuity is something about which I have said nothing just yet. I address this issue in the final section of this chapter, as well as in Shoemaker $2011 \mathrm{~b}$.
} 
persisting instantiation of those sophisticated forensic capacities, i.e. psychological continuity. Thus is born the psychological criterion of identity.

However, if the psychological criterion is explicitly coupled with the view that we persons are essentially persons, then it seemingly cannot account for some rather obvious truths, such as the fact that I was once a fetus, or that I could fall into a permanent vegetative state (PVS) (given that I who am essentially a person could not have been otherwise, whereas fetuses and those in PVS are indeed otherwise; they are nonpersons). ${ }^{9}$ Animalism here rides to the rescue: I was once a fetus and I could fall into PVS precisely because what I am essentially is an animal compatible with all sorts of phases, including my current personhood phase. But animalism gains in plausibility on the essentialist score only seemingly to undermine the presumed connection to practical concerns. The concerns are attached (so the Lockean story goes) to personhood, to sophisticated psychological capacities, but as it turns out the story about personhood is a story about what we do-we reason, reflect on ourselves, form intentions, etc.whereas animalism is a story about what we are, so if the animalists are right, it looks like the forensic aspect of persons just can't be about identity in the end. ${ }^{10}$

Schechtman reveals why this story is still problematic, however, by considering a bioethical issue having grave practical importance, namely, advance directives. The difficult issue seems to be whether or not the patient before us with severe dementia who needs extraordinary measures to keep her alive is identical to the person who signed the advance directive $\mathrm{AD}$ ) five years ago stating that no extraordinary measures were to be taken to keep her alive. ${ }^{11}$ The advocate of the psychological criterion will likely say that the severely demented patient just isn't a person, so the AD no longer applies (although what's in the best interest of the patient may still dictate not deploying extraordinary measures, or the previous person's "surviving interests" as laid out in the $\mathrm{AD}$ may determine what is to be done with her living "remains"). ${ }^{12}$ This response is unsatisfying, however, because it suggests that there remains no rational grounding for the concerns we may have for this patient persisting in the face of this verdict. Suppose my mother was the one who signed the AD. If my mother is truly no longer in existence now, why should it bother me as it does to see the demented person before me in this way? Indeed, what grounds could I have for continuing to care for this woman, for treating her with love and affection (Schechtman 2010: 275-6)? There are, it seems, concerns that (reasonably) persist toward those whose psychological robustness has considerably waned.

Alternatively, the animalist at least gets the identity part of the story right: this is indeed my mother before me (and so she is identical to the signer of the $\mathrm{AD}$ ), albeit sans

\footnotetext{
9 See, e.g., Olson 1997: ch. 4.

${ }_{10}$ More precisely, it can't be about numerical identity. Olson 1997's insightful discussion in chapter 3 (about which more below) offers the possibility of a "same person" relation that accounts for the forensic features of persons but can't meet the logical demands of the numerical identity relation.

${ }^{11}$ I argue against this reading of the issue in Shoemaker 2010.

12 See, e.g., Buchanan 1988: esp. 286-7.
} 
(robust Lockean) personhood. But if animalism goes on to divorce completely what we are from what we do, its truth has no practical implications for my interactions with this woman in these circumstances. As Schechtman puts it:

The animalist need not deny that we might for some reason decide to place practical significance on the brute fact of the continuation of a single individual, but on this view, it is somewhat mysterious why we should ever decide to do so. In our actual lives, however, we do not seem to need an extra step to explain why it should be of practical significance to me that the individual suffering in a hospital bed is the mother I loved; nothing feels more natural than that it should. Animalism thus fails to capture a direct and immediate connection between identity and practical concerns that is a forceful part of our lived experience. (Schechtman 2010: 276-7)

That she is my mother is sufficient to explain my ongoing affection for her, goes the thought; her life is simply intertwined with mine. But we cannot squeeze out what ought to be this practical implication from the stony metaphysical heart of animalism.

The overall problem that Schechtman identifies, then, is that advocates of both animalism and psychological criteria think that our practical concerns are associated solely with a robust conception of Lockean personhood. If we are essentially such persons (and so our persistence conditions are psychological), then we get the desired practical implications, but only at the cost of metaphysical implausibility. If we are essentially animals (and so our persistence conditions are biological), then we gain metaphysical plausibility, but only by losing the desired practical implications. Schechtman's solution is thus to broaden the (forensic) understanding of personhood so as to incorporate the metaphysical insights of animalism in a way that allows that theory to produce the desired practical implications.

She does so by taking our practical concerns and commitments as foundational and then recognizing that humans aren't the only animals to have such concerns and commitments. Other animals also care for their young and have friendly relations with others and seek out pleasure and avoid pain, etc. Now we happen to have concerns in addition to these that are unique to our biology and way of life, but the set of concerns in itself is continuous with those of other animals. We are human animals who typically live certain sorts of lives, various elements of which are the targets of our practical concerns. Schechtman thus proposes to understand "person" as a creature living a "person-life" and a person-life as the "kind of life typically lived by an enculturated human" (Schechtman 2010: 278; cf. Schechtman 2014: ch. 5). But there is a wide variety of concerns attaching to this sort of life, including the various ways we have of loving and treating Lockean non-persons such as infants, adults with cognitive disabilities, and those in PVS. It is true, of course, that we treat full-fledged moral agents in additional sorts of ways - we hold them responsible, for one thing - but this sort of treatment is simply continuous with the sort of treatment just mentioned. It is just one form our practical interactions may take, one we reserve for those with certain more developed sorts of human capacities. 
Person-lives will be very closely associated with the animal-lives targeted by animalism, but there are some crucial differences. It is not solely, primarily, or even necessarily in virtue of our biological nature that we have person-lives; it is, rather, in virtue of our anthropological nature that we do so (a feral human child may not have such a nature). The relevant lives are the lives of enculturated humans, after all (and so it is possible that non-humans could also have such lives). Nevertheless, the standard case is one in which these sorts of person-lives just overlap with our animal lives, such that the end-points of both are the same, as are the biological conditions of their preservation. So insofar as the two sorts of lives typically share these features, the relevant gap might be bridged between identity and the practical concerns: that she is my mother, for example, will indeed be sufficient to explain and ground my ongoing affection for the demented patient before me, given that such concern is a direct implication of her being the same person - the same enculturated human animal whose life is intertwined with mine-as the woman who took care of me as a child. Animalism thus may be altered and adopted to resist Challenge. The continuity of our animal life, in the world as we know it, would be a crucial constituting element of our personhood in this broader sense. The key would be to ground our practical concerns in the types of animals we are. That we are animals is thus important, but it is not what matters most, which is that we are human animals. To the extent that our animal identity is a constituting component of our person-life identity, though, it at least may be said to be a constituting component of the practical concerns targeting that life..$^{13}$

This seems a more plausible route to resisting Challenge than DeGrazia's in two respects. First, insofar as biological continuity is a necessary condition for our practical concerns in both approaches (in typical cases), it at least plays a more directly relevant constituting role in the person-life view, for our humanity is much more directly a function of our animality on Schechtman's picture. Second, the appeal to "the world as we know it," is far less ad hoc on Schechtman's view, for the world as we know it is precisely the world in which we have evolved the relevant practices, the practices central to our enculturated humanity. Restricting the analysis to "the world as we know it" on Schechtman's approach thus at least explains why appeals to hypothetical future teleporters and fissioners are less relevant to our enterprise, for who are those future beings to us and our concerns? We can plausibly speak only about who we are and what we care about (see Schechtman's own discussion of fission in Schechtman 2014: 159-66).

I find Schechtman's overall discussion of this issue sensitive and insightful. But whereas DeGrazia's reply to Challenge gives an account of the "proper fit" between identity and our practical concerns that is too tight (providing a very constricted explanatory story), the Schechtmanian account embodied in this sort of reply to

\footnotetext{
${ }_{13}$ This should be flagged as my own liberal extrapolation from Schechtman's earlier (2010) view, a view that itself is not intended to rescue animalism from any challenges at all. Indeed, Schechtman rejects animalism in favor of her own distinct person-life view in her 2014: ch. 7.
} 
Challenge is too loose. ${ }^{14}$ To see what I mean, consider the following analogy. Suppose our family has a dog, and as our young daughter sees the dog and me interacting in various ways, she asks for an explanation. "Why do you take him out to pee?" she asks. "Why do you feed him this kind of food?" "Why do you play with him by throwing the tennis ball in the yard?" "Why does he bark when the doorbell rings?" "Why is he walking outside with his nose to the ground?" "Why do you take away his toys when he chews up your papers?" Suppose that I reply to each of these queries in precisely the same way: "Because he's a dog." In each case my reply is true, and in each case it is equally uninformative. That's because every one of my daughter's questions is tracking a different aspect of our dog's nature and his relation to us-e.g. his protective instincts, his sensory capacities, his doggy discipline, his digestive nature, his toilet abilitiesand my answer conflates these importantly distinct elements of dog-ness for the sake of a simple explanation.

I believe the Schechtmanian reply to Challenge does the same thing. ${ }^{15}$ There are importantly distinct elements of our personhood (or person-lives) that are being glossed on this story. Every answer to a question about what grounds the different practical concerns appeals simply to the sameness of the person-life at issue. So "Why do you care about the demented patient before you?" "Because she's living the same person-life as the woman who raised me." "Why should we hold this guy responsible for that past action?" "Because he's living the same person-life as the guy who performed it." "Why should we compensate this woman for the injuries to that fetus in the ultrasound picture?" "Because she is living the same person-life as that fetus." "Why am I justified in anticipating the experiences of some partygoer next week?" "Because the person whose experiences you are anticipating will be living the same person-life as you." And so on. But each of these questions is, I suggest, asking about a different distinct element of those person-lives: we want to know what it is about the person-life that grounds our concern in each specific case (just as my daughter was surely asking what it is about our dog's dog-ness specifically that grounds our various interactions with him in each case). So while the Schechtmanian answer to each question may be true, it doesn't seem to give us what we want. As I said earlier, when investigating the relation between identity and our practical concerns, what the Challengers are looking for is a robust, informative explanation of the justificatory role played by identity qua

\footnotetext{
${ }^{14}$ And again, I use "Schechtmanian" here because it is not Schechtman's aim to respond to Challenge at all.

${ }^{15}$ Here is the spot where Schechtman herself would get off the boat, I think, for she merely takes her account to provide a unifying story about the locus of such questions and concerns, i.e. what is the thing which all these questions and concerns are tracking, and what unifies that thing for these purposes? (See, e.g., Schechtman 2014: chs. 1-2.) Consequently, if we just want to know what it is to be a (domesticated) dog, the answer could well be that it's a creature that has protective instincts, sensory capacities, a digestive nature, certain toilet abilities, discipline, etc., and what unifies these various features has to do with facts both about canine biology and domestication and the sorts of lives such dogs lead (as informed by evolution in particular sorts of environments, say). This all seems right to me. What I object to, then, is the extension of this view to ground our specific practical concerns in a way that allegedly vindicates animalism.
} 
necessary condition for those concerns. While certainly robust (it purports to explain all of our practical concerns), the Schechtmanian answer seems uninformative: it doesn't yet explain the presumably crucial connection between identity (of these more broadly construed "persons") and the practical concerns, the connection that also presumably renders a theory of identity more or less plausible.

Now the response just given should be taken as merely suggestive and preliminary, for I have not yet shown that our questions about the practical concerns really are distinct from one another or that they really track more specific aspects of our personlives. This will be the task of the final section of the chapter. But before embarking on that project (and also to motivate it further), I need to explore the possibility of a very different response to Challenge, namely, that the degree of "fit" between a theory of identity and our practical concerns is actually independent from the plausibility of that theory. If this response is correct, then the tightness or looseness of some purported fit between them will be irrelevant.

\section{Divorcing Animalism from Our Practical Concerns: Olson and Transplants}

In making his case for animalism, Eric Olson is first concerned to undermine the most powerful argument in favor of its rival, what he calls the Psychological Approach. What seems to do the most work in its favor is the reaction people have to the following story: suppose Prince's cerebrum were transplanted into Cobbler's skull, resulting both in someone with Cobbler's body but Prince's psychological characteristics ("Brainy"), and someone else more or less in a persistent vegetative state with Prince's body and no cerebrum ("Brainless"). What happened to Prince when his cerebrum was transplanted into Cobbler? Most people's strong intuition here is that Prince survived in Cobbler's body, that Prince is Brainy. This is what Olson calls the Transplant Intuition, the hunch that persons go where their cerebrums (preserving psychological continuity) go (Olson 1997: 42-3). If our intuition is that Prince survives the transplant as Brainy, then it seems we are therefore committed to the Psychological Approach to personal identity.

Not so fast, though, argues Olson. Instead, he suggests, we can have the Transplant Intuition without accepting the Psychological Approach. This is because the Transplant Intuition actually may just be tracking our practical concerns, and so may be prized apart from a commitment to any particular theory of numerical identity. Consequently, it may well be equally compatible with both the Psychological Approach and animalism.

In making this point, Olson explains and defends what he calls the "Parfit-Shoemaker Thesis," the view that our practical concerns don't always track numerical identity. ${ }^{16} \mathrm{Olson}$ specifically considers three such concerns: prudential concern, moral responsibility,

${ }^{16}$ See Olson 1997: 54, for this formulation with respect to prudential concern. 
and social treatment. Regarding the first, in the fission case I might well have the special sort of prudential concern for my fission products that is typically reserved only for myself. So were I about to undergo the division (resulting in two people who would be exactly similar to me), it could be perfectly justifiable for me to have special concern for the prospects of both, despite the fact that neither (on the standard story) could be me (Olson 1997: 54-5). ${ }^{17}$

Regarding the second concern, one might well be justifiably held accountable for the actions of someone else. If Prince performed some bad action pre-transplant, it seems we could hold Brainy accountable for Prince's action, regardless of whether or not Brainy was Prince. Now one might still insist that the accountability here obtains precisely because Brainy is Prince, but then consider a different case: Prince dies during the initial operation, and several days later technicians build a perfect replica of him and install Prince's preserved cerebrum into the replica's head. Prince is certainly dead; this is merely a duplicate (call him Duplicate). Nevertheless, it could well be appropriate to hold Duplicate accountable for Prince's actions. Accountability seems to depend on psychological continuity, but this relation could obtain independently of numerical identity. Indeed, it would surely obtain without numerical identity if animalism were true (Olson 1997: 57-62).

Finally, consider social treatment. Presumably everyone will treat Brainy as Prince once they find out what happened or they talk with him a bit: the hospital will allow visitations for Brainy from Prince's wife and the Queen, Brainy will have access to Prince's bank account, Prince's friends will view Brainy as Prince, Brainy will raise Prince's kids and pay his bills, and so on. Additionally, Olson turns the screws by considering the duplication case again: everyone would likely treat Duplicate in this way too, but that means that numerical identity and this particular practical concern are surely prized apart. Thus the fact that social treatment seems to track psychological continuity neither increases the plausibility of the Psychological Approach nor decreases the plausibility of animalism, as it is equally compatible with both.

In each case, then, the practical concerns may be divorced from numerical identity. Olson's thought (what he calls the "bold conjecture" (Olson 1997: 69)) is that the Transplant Intuition is really about our practical concerns (which "are closely connected with psychological continuity" (Olson 1997: 70)), and not about numerical identity. So we may think that, because Prince would be warranted in having special concern for Brainy, and because Brainy would be accountable for Prince's actions, and because others would treat Brainy as if they would have treated Prince, the psychological continuity that grounds those practical concerns delivers numerical identity as well, insofar as identity is thought to have practical importance. But given that these concerns could be grounded (on psychological continuity) regardless of whether or

\footnotetext{
${ }_{17}$ On a four-dimensionalist ontology, however (an ontology Olson later rejects), there may be a way to preserve the tracking relation between prudential concern and numerical identity even in the fission case. See, e.g., Lewis 1976 and Sider 2001.
} 
not numerical identity obtains, we may deny the view that numerical identity has practical importance, and thus effectively block Challenge. Animalism could be true despite its failure to account for our practical concerns in the robust, informative sense.

I am less concerned here to evaluate Olson's success in disabusing the Transplant Intuition of its force in establishing the Psychological Approach than I am in evaluating the success of an approach like his (call it Olsonian) in resisting Challenge. And on this point, a genuine worry remains: even if the Transplant Intuition is really tracking our practical concerns and not numerical identity, that doesn't yet mean that numerical identity has no practical importance, that the plausibility of a theory of numerical identity doesn't increase or decrease depending on the extent to which it fits with our practical concerns. In other words, just because our practical concerns might track a relation-psychological continuity-which itself may not hold uniquely (in fission) or may obtain in duplicates, that doesn't yet show (a) that psychological relation isn't what matters in numerical identity, and therefore (b) that psychological relation isn't (at least) a necessary condition for numerical identity.

This is a subtle but important point. Olson draws primarily from Parfit, adopting the motto that "identity is not what matters," i.e. numerical identity has no practical import (Parfit 1984: ch. 12). But this motto may be taken in one of two ways. On the one hand, it might mean that there are two necessary aspects of numerical identitypsychological continuity (let us stipulate) and uniqueness-and where psychological continuity without uniqueness obtains, numerical identity is absent, but so what? Everything that matters (i.e. psychological continuity) still obtains, so nothing of importance is lost when numerical identity in this sense is lost, i.e. when uniqueness is absent. This is Parfit's own take on the motto (Parfit 1984: 262-4). On the other hand, it might mean that none of the relations or elements in which numerical identity consists matter, so that the correct theory of personal identity will contain nothing of relevance to our practical concerns. ${ }^{18}$ The most Olson has done is support the first interpretation. What is needed to thwart the second premise of Challenge, however, is support for the second, stronger interpretation. ${ }^{19}$ Otherwise, it remains open to an advocate of Challenge to say, "True enough, my intuitions may be tracking the practical concerns grounded in psychological continuity, and psychological continuity on its own isn't sufficient to establish numerical identity, but it still must be the primary necessary ingredient in identity because of its connection to our set of practical concerns, so the Psychological Approach nevertheless gains in plausibility over animalism." ${ }^{20}$ It is my

\footnotetext{
${ }^{18}$ I am stipulating away here non-reductionism about personal identity, the view that the facts of personal identity simply don't consist in more particular facts about brains, bodies, and series of interrelated mental and/or physical events. See Parfit 1984: 210 and throughout part III for discussion.

${ }_{19}$ And I should make it clear that, for Olson's own purposes, what he has done is sufficient. Again, I'm taking up a possible Olsonian response to Challenge, and for that to succeed, it will have to involve a stronger thesis than Olson's.

${ }^{20}$ Consider how this would work with respect to what Olson takes to be his knock-down case, wherein Duplicate resides. The advocate I have just described might simply deny Olson's stipulation that Duplicate is indeed a duplicate. To the extent that psychological continuity (with any cause) can bridge gaps in its
} 
aim in what remains to rebut this last challenge by supporting the stronger interpretation of "identity is not what matters."

\section{The Pluralism of the Practical}

Olson's version of the practical unimportance of numerical identity stems from consideration of three practical concerns (prudence, responsibility, and social treatment) that are assumed to be (a) the only relevant practical concerns at issue, and (b) unified in virtue of being grounded in psychological continuity. Both assumptions are mistaken, however. ${ }^{21}$

Regarding (a), I have already noted that there are several other possible person- or identity-related practical concerns at issue, including compensation, anticipation, and emotional patterns. These could be relevant to bolstering the strength of the Transplant Intuition, as we might also be thinking of how Brainy could be compensated for burdens underwent by Prince, or how Brainy could justifiably feel pride at the past actions of Prince, or how, if he knew the transplant was coming, Prince might justifiably anticipate the experiences of Brainy. Alternatively, they might be thought to bolster the Challenge that, by also tracking psychological continuity, they still track what matters in numerical identity. My only point in reminding us of the additional practical concerns, though, is that their presence, in addition to those discussed by Olson, actually makes my main case, which is against (b), more stark.

Let us turn, then, to that case. The basic assumption I want to argue against is that our practical concerns constitute a unified set that is grounded on psychological continuity. What is actually the case, I will urge, is that the grounding relation is neither psychological continuity nor, ultimately, identity; it is, rather, ownership, which itself takes multiple forms, and so is not capturable under any kind of explanatorily robust, single rubric. In order to see both the meaning and force of this point, however, we need to examine each of the relevant practical concerns in more detail.

To provide a glimpse into what I think of as the pluralism of the practical, we may start by considering one of the practical concerns Olson himself discusses: social treatment. While we may at first be inclined to go along with his thought that social treatment in the Prince/Cobbler case tracks psychological continuity, further reflection suggests that the matter is far more complicated than he lets on. Indeed, it turns out that by emphasizing different possibilities we may come to think that social treatment actually

biological underpinning, it could still preserve what is necessary to numerical identity, and given that uniqueness also obtains in this case, Duplicate may well be me as a result.

${ }^{21}$ In a way, Olson recognizes this point. In an insightful speculative passage, he briefly mentions that it might be implausible to believe that the three concerns he discusses "always go together" (Olson 1997: 66), and he admits that there may be "additional relations of practical concern associated with personal identity besides the three we have discussed" (Olson 1997: 68). But in neither case does he sufficiently explore what this might mean for the general thesis that our practical concerns are not necessarily connected at all with personal identity, such that the plausibility of animalism isn't dependent on how it accounts for them. It is my aim in what follows in the text to take up this burden. 
tracks biological continuity. For example, consider someone who, due to some traumatic brain injury, undergoes radical psychological discontinuity. She will still be treated as the owner of the pre-transformation-person's car and other property, and she will also be treated as the spouse of the pre-transformation-person's spouse, the daughter of her parent, and so forth. Indeed, parenthood provides an excellent general case: expectant mothers often treat their fetuses in loving ways from early in pregnancy, and while their specific expressions of love may change for that growing organism in ways rendered appropriate by its different phases, there remains an ongoing target of these expressions, and they are clearly tracking biological continuity. The ongoing specific love is targeted at a human animal, from fetushood through infancy, toddlerhood, adolescence, adulthood, senescence, and even, perhaps, to a vegetative state (I take it that both DeGrazia and Schechtman advance versions of this point as well). That the Queen would thus so blithely switch her loving expressions from Brainless (Prince's body sans cerebrum) to Brainy is actually no foregone conclusion. The special concerns of parenthood are tied tightly to our biological natures.

One might respond to these examples by embracing pluralism about our social treatment concerns but only in order to embrace a pluralism about identity, suggesting that different sorts of identity relations obtain depending on the form of treatment in question. ${ }^{22}$ Such a response would maintain the view that personal identity is what has practical importance. In what follows, I hope to undermine this response by focusing precisely on the details of each practical concern in question, and so by investigating what really is being tracked in each case.

Responsibility: ${ }^{23}$ The relevant platitude is that I can be responsible only for my own actions, and what is thought to make an action my own is that I am numerically identical to the person who performed it. But there is a conceptual wedge we can introduce here: my ownership of some action is distinct from my identity with its agent. The straightforward reason is just that each involves two different relata: ownership is a relation between an agent and actijon, whereas numerical identity is a relation some individual bears to itself (quaindividual). And what I take the actual lesson of the fission case to be is a revelation of how ownership of this sort may be prized apart from identity. If I perform A and then divide, A may still be properly attributable to both of my fission products despite their not being numerically identical to me (on pain of their being numerically identical to one another). ${ }^{24}$ But we can also see this phenomenon at

\footnotetext{
${ }^{22}$ For instance, one might think that a biological criterion is true of us qua moral patients (e.g. as children) but that a psychological criterion is true of us qua moral agents (e.g. as bearers of various financial and parental obligations). I don't know of anyone who has held a view like this, but it's not prima facie implausible. (Perhaps Locke's view-distinguishing between man and person, with different identity conditions for each-comes closest.)

${ }^{23}$ The arguments in this paragraph are drawn from Shoemaker 2011a.

${ }^{24}$ If a four-dimensionalist is unhappy with this treatment of the case, she could instead imagine a version of Olson's duplication case, where my duplicates may still properly be thought to own my previous actions, despite clearly not being me.
} 
work in real world cases: I may be the joint owner of actions produced by a joint agent. When we have sex, or sing a duet, or rob a bank, or win a game, we contribute to joint acts of joint agents; these are actions a we, not an I, performs. But even though I am not identical to that joint agent (on pain of being identical to all the other contributors to it), I may own that agent's actions for purposes of responsibility. ${ }^{25}$ So here is another reason to distinguish ownership from numerical identity: ownership isn't a uniqueness (1-1) relation, whereas numerical identity is. Finally, there are real life cases in which ownership of actions is divorced from performance of them. If I order my children to run around breaking valuables in your house, those actions are attributable to me (I own them), despite the fact that I didn't perform any of them and so cannot be identical to their agent. ${ }^{26}$

So what does ownership-with-respect-to-responsibility consist in? As we have seen, theorists on both sides of the personal identity divide are at least united in agreeing that this ownership relation consists in psychological continuity. As it turns out, though, psychological continuity is neither necessary nor sufficient for ownership in this arena. It is not sufficient, because if I gradually go into and out of a fugue state during which my values and volitional make-up are radically changed, I will, postfugue, be psychologically continuous with that person in the fugue state (because of the gradual nature of the transformation) without his actions being mine. It is not necessary, because it is possible to undergo psychological discontinuity (from a blow to the head, say) while preserving ownership of the pre-trauma action just in case the small number of values or concerns constructing one's volitional network at the time of action have been preserved post-trauma. What all of this suggests instead, then, is that responsibility-ownership consists in something like the preservation of the psychological elements contributing to one's volitional network, but this may be very different from psychological continuity full stop. ${ }^{27}$

\footnotetext{
${ }^{25}$ One might think that in such cases I have only partial responsibility, tracking my limited degree of attributability as it coincides with my limited degree of participation in the original joint action. I don't think this is correct. Instead, I think individual members of joint agents are often fully responsible for their joint action. Suppose there five of us who rob a bank. One of us points a gun at the tellers, one of us shoves the money into a bag, one of us keeps a gun on the security guard, one of us serves as a lookout, and one of us awaits in the getaway car. The joint action-robbing the bank-strikes me as fully attributable to each of us individually. Suppose, for example, that only one person robbed the bank. The degree of ownership (and subsequent responsibility) attributed to him will be equal to that assigned to each of us in the joint robbery case (to the extent it makes sense to talk in terms of degrees of attribution). This doesn't mean there's more responsibility (five times as much) in the joint robbery case; rather, it means that the notion of full responsibility (which presupposes full ownership) isn't additive. I take what I'm saying here as akin to Harry Frankfurt's example of our simultaneously flipping two light switches at either end of a room that control the same bulb. As he puts it, "Neither person is solely responsible for the light's going on, nor do they share the responsibility in the sense that each is partially responsible; rather, each of them is fully responsible" (Frankfurt 1988: 25, n.10).

${ }^{26}$ It's not just my ordering them to break the valuables that I am responsible for; it is, I maintain, their actual actions. This is because what they've done is directly dependent on my will. This is also why, for example, a general who orders his troops to take the bridge may be responsible for that action if they are successful. That the children or the troops are able to refuse the orders may render them also complicit in the actions, and so co-owners of them as well.

${ }^{27}$ This final suggestion is fleshed out in Shoemaker $2011 \mathrm{~b}$.
} 
Anticipation: The assumed platitude regarding anticipation is that I am justified in anticipating some set of future experiences only if they are mine. And again there is thought to be a connection between the ownership of those future experiences and numerical identity: what makes those experiences mine is just that I will be the person who experiences them. This seems once more to suggest a psychological continuity theory of identity. But anticipation-ownership is a relation between an experiencer now and some future experiences, whereas identity (as it is relevant here, anyway) is a relation between experiencers. And anticipation-ownership clearly seems divorceable from identity: were I about to undergo fission, I could certainly anticipate the experiences of each product, viewing them both as mine, whereas identity between us would not obtain. Relatedly, were I to entertain undergoing fusion, I might be able to anticipate the experiences of the fused experiencer, despite that experiencer (likely) not being me. ${ }^{28}$ Anticipation-ownership is not a uniqueness relation, whereas numerical identity is.

So what does anticipation-ownership consist in? Once again, psychological continuity (prized apart from identity) might be thought at least to be what matters, but that is actually too broad. Instead, all that seems to be needed is some kind of properly connected stream of conscious awareness. Perhaps one might want to insist on the additional persistence of relevant values (in order for the various features of the anticipated experiences and the actual experiences to be viewed in sufficiently similar evaluative light and so themselves to be sufficiently similar for the process to count as anticipation), but this doesn't seem necessary either, given that it ought to be possible for a wanton-someone who values and cares about nothing - to anticipate future experiences as well. But I leave this possibility open for future analysis.

Self-concern: Here what may seem to be going on is that I have a special sort of concern only for the person in the future who is $m e$. Isn't this, then, clearly an identity-directed concern? "Self-concern" is what Mark Johnston calls the clearest example of "a wider pattern of self-referential concern, directed outwards from one's present self to one's future self, one's friends, family, acquaintances, neighbourhood, and so on" (Johnston 1997: 156; emphasis mine). True enough. But then what really unites all of these varieties of "special" concern is the mineness attached to them: the concerns are for my self, $m y$ friends, $m y$ family, etc. This suggests again, though, that the grounding relation is ownership, which could well run independently of identity. ${ }^{29}$ Were I destroyed as I sleep tonight and a duplicate put in my place, it seems that the mineness of the self, friends, family, and acquaintances with respect to special concern could be preserved

\footnotetext{
${ }^{28}$ For a similar argument applied to Don Marquis's anti-abortion argument, see Shoemaker 2010: 485-6.

${ }^{29}$ Johnston's point (Johnston 1997: 158-9) is that these self-referential concerns are ungrounded, or at least self-grounded independently of the metaphysics of identity. What I am suggesting, however, is that even if the latter is true, they may still have to answer to the metaphysics of ownership. In other words, my having this sort of special concern for someone to whom I don't bear the mineness relation would likely be unjustified (or at least very weird).
} 
in the duplicate despite the loss of identity, and despite the fact that the duplicate didn't make any of those friends or acquaintances, say, or wasn't around for the genesis of the family or the original self. Consequently, it seems that this sort of ownership consists in yet another psychological relation, a kind of persistence or resemblance relation between the values and attitudes directed toward the relevant object (the entities filling the roles of self, friends, family, etc.), along with connections of memory (or q-memory), intentions, beliefs, desires, and goals relevant to those cared-for objects. This sort of ownership, then, does indeed start to sound like robust psychological continuity.

Compensation: This requires a more complicated analysis. Here is the relevant platitude: I can truly be compensated with a benefit for a burden only if the burden underwent was my own. This platitude is then taken to entail the view that compensation presupposes personal identity: some burden could be my own if and only if I am numerically identical with the person who underwent it. ${ }^{30}$ This entailment does not obtain, however. Some past burden may be mine without my being numerically identical to the one who was burdened. In science fiction cases, this could be true of one of the fission products with respect to some pre-fission burden, and it could also be true of Duplicate with respect to some burden underwent by me. In real world cases, I may be legitimately compensated for a burden undergone by a joint agent to which I contributed. For example, for the sacrifices made by a team on which I myself personally sacrificed very little (perhaps I was injured or rode the bench), I may still warrant compensation equal to everyone else. But I am not identical to that joint agent, that team, on pain of being identical with every other player who would ostensibly be identical to that joint agent as well, despite the team's sacrifice being (partially) mine.

It may seem that compensation-ownership consists in psychological continuity, but I believe this is false. Suppose Johann suddenly enters a fugue state. Call the radically psychologically discontinuous "fuguer" Sebastian. Suppose that I had broken Johann's wrist prior to the fugue state but that I now have the medical equipment and expertise to completely heal it and, indeed, make it stronger than before (i.e. to "rejuvenate" it). When I rejuvenate the wrist I broke, it is Sebastian's. Does what I have done count as compensation? It certainly seems so, despite the psychological discontinuity between Sebastian and Johann. This is because the kind of burden I attempted to rectify was to Johann's animal self, and while physical setbacks are, at most, merely instrumental to well-being-on any account of well-being, I think-if they persist across multiple psychological beings, they may be instrumental in reducing the well-being of whomever they are attached to. To rejuvenate the specific wrist I broke (attached to a living human being) is to make right a burden I caused.

\footnotetext{
${ }^{30}$ Parfit explicitly takes to be "clearly true" the view that compensation presupposes personal identity (Parfit 1984: 337), and Diane Jeske agrees, saying that "if you are to compensate me for a burden imposed on me, then you must provide me with some counterbalancing benefit" (Jeske 1993: 560).
} 
Whose burden did I rectify, however? We could say that I clearly burdened Johann, so I must have compensated him. Alternatively, we could say that I clearly compensated Sebastian, so I must have burdened him. If we take only one of these construals to be true, though, we are overly attached to the thought that compensation presupposes personal identity, i.e. that it tracks the identity of psychological beings. But there remains another, more plausible, option: there is a persisting animal here, call him Bach, whose interests were set back when his wrist was broken but whose injury was made right when his wrist was later rejuvenated. That he underwent radical psychological discontinuity during this period is irrelevant, for his interests qua animal were sufficient to generate the grounds for compensation for the injury to his animal body.

This last way of construing matters might suggest that identity is actually still grounding compensation, but now just animal identity. This would be too quick, however, for compensation may also coherently cut across different animals. This is presumably the case in the Prince/Cobbler scenarios. Suppose I psychologically injured Prince, causing certain traumatic flashbacks to occur, but I was able to eliminate such flashbacks by fiddling with the cerebrum from which they were produced. Doing so when the cerebrum is installed in Brainy strikes me as compensation for the burdens of Prince, despite the lack of animal continuity between them.

We might, therefore, ultimately be tempted to say this: yes, compensation-ownership may sometimes be grounded in animal continuity and may sometimes be grounded in psychological continuity, but in either case it would still be grounded in numerical identity, which would preserve the original assumption that compensation presupposes identity. To explain, we could say that when the injury is to one's (non-psychological) physical self, a benefit may compensate for that burden if and only if the benefited individual is the same animal as the burdened individual, whereas when the injury is to one's psychological self, a benefit may compensate for that burden if and only if the benefited individual is the same person-psychological entity-as the burdened individual. On this construal, then, compensation-ownership still presupposes identity, but because there are different kinds of compensation, there must be multiple identity relations grounding ownership for each kind.

This response will not work, however, for we cannot be pluralists about numerical identity; we can only be pluralists about ownership. If the numerical identity we are talking about is identity of individuals like us, then the proposal just given could require that I am both identical with, and not identical with, some past or future individual. This could be the case, for example, with respect to an injury caused to Johann pre-fugue, an injury affecting both his physical and psychological selves, e.g. if I stabbed him in the brain, causing him both physical trauma and psychological trauma. Suppose the stabbing caused both impaired motor skills and the loss of a central value, perhaps the love of cats which had guided the projects of his adult life. He then enters the fugue state and Sebastian is "born." In this state, given his radical psychological discontinuity from Johann, Sebastian embarks on a very different life project, pursuing a brand of stand-up comedy that centrally involves making fun of cats and cat lovers. Suppose 
I have the ability to heal the portion of the brain I had destroyed. Were I to do so, I would compensate Sebastian with respect to his physical (animal) self-restoring his motor skills-but would not compensate Sebastian with respect to his psychological (personal) self, for introducing a love of cats would probably undermine his stand-up comedy dreams. On the above proposal, then, Sebastian both is and is not identical to Johann, the individual who underwent the original burden: to the extent Sebastian is (physically) compensated for the injury to Johann, they are one and the same; to the extent he could not be (psychologically) compensated by the very same treatment for that very same injury, they are not. ${ }^{31}$

I think, then, that this last-ditch effort to preserve some relation between compensation and numerical identity must be abandoned..$^{32}$ If all we are tracking when we are distributing a compensatory benefit to someone is that the burden it outweighs was his, it is just irrelevant whether or not that compensation-ownership relation happens to correspond to some numerical identity relation or other. All that matters is whether or not compensation-ownership in any particular instance is attached to the agent's physical or psychological self, and this in turn will be determined by the specific nature of the benefits or burdens in question.

While we cannot coherently be pluralists about numerical identity, therefore, we nevertheless can and ought to be pluralists about compensation-ownership (and ownership generally). Individuals like us are numerically identical only to ourselves, whereas, given the wide variety of physical and psychological elements we have, individuals like us may be many different kinds of owners.

This point returns us to the heart of my worry about the implications of the Schechtmanian proposal: expanding the notion of personhood in the way suggested there glosses over the wide variety of relations that actually ground our person-related practices, and so fails to do any real explanatory work. What is doing the explanatory work instead is the ownership relation, with its multiple and varying instantiation conditions, whereas talk of identity doesn't help and may actually hurt (by distracting our attention away from the actual conditions of ownership). Identity is the reddest of herrings. ${ }^{33}$

${ }^{31}$ Perhaps there were really two injuries, one to his brain and one to his psychology? Perhaps, but it seems more plausible to describe it as one injury with multiple manifestations. For example, if I break your hand, it will hinder you as a driver and as a cook. But there is only one injury, namely to your hand; it would be odd to say that I injured your driving hand and I also injured your cooking hand. At any rate, though, what matters most here is the form of compensation: I undid to Sebastian's brain precisely what I did to Johann's brain. That this only counts as compensation for one of the injury's manifestations is what generates the contradiction when tied to identity.

${ }^{32}$ And I think similar contradictions could be derived for the previously discussed practical concerns as well.

${ }^{33}$ Perhaps, though, there are some other practical concerns for which identity is important? The only ones that would seem to have a chance are the concerns surrounding third-person reidentification. I actually believe that considerations of ownership are more fundamental in such cases too, although space constraints prevent me from laying out this case in any detail here. The basic idea, though, is that where we have concerns regarding reidentifying others, they are often-albeit definitely not always-with respect to an extension of the sort of special concern we have for ourselves. I have already cited Johnston's plausible 


\section{Conclusion}

The Challenge to animalism is that it is rendered less plausible in virtue of its lacking a proper fit with our practical concerns. After exploring and expressing worries about two attempts to show how animalism might not lack the relevant practical fit, I turned to an Olsonian defense of the view that lacking this fit has no effect either way on the plausibility of animalism. While Olson's own attempt at making this case does defend against a weaker interpretation of Challenge, it doesn't defend ${ }^{34}$ against a stronger interpretation, according to which the psychological continuity assumed to ground and unify our practical concerns must still be at least the primary necessary ingredient of numerical identity. In the final part of the chapter, I tried to undermine this case by showing that (a) our practical concerns are not a unified set; (b) different concerns are grounded on different relations, most of which (perhaps all) are not psychological continuity; and (c) because at least some individual practical concerns (e.g. compensation) themselves are grounded on multiple, competing forms of ownership, there can be no entailment from ownership to numerical identity without contradiction.

Because of the surface similarity of the view I have expounded to previously articulated views of others, I want to spend the remainder of my concluding time here noting those similarities in order to spell out what I take to be some new and crucial differences. It may seem, first, that my view is simply a revisiting of Parfit's "Identity Doesn't Matter" view, according to which what matters instead (given thought experiments like fission) is just psychological continuity and/or connectedness (Relation R); the uniqueness relation that combines with $\mathrm{R}$ to deliver numerical identity is unimportant (Parfit 1984: 253-66). What I have tried to show, by contrast, is that not only does uniqueness not matter; neither does Relation R. Now Parfit's is officially a story about what matters in survival, but he takes this mattering to extend across the board to all of our practical concerns. Nonetheless, what matters in survival may well not be what matters for anticipation, responsibility, compensation, self-referential concerns, and so forth..$^{35}$ Indeed, we have good reason to believe that these concerns are grounded in

understanding of self-concern, which is just the most central case of self-referential concerns like those extended to one's family, friends, acquaintances, loved ones, and so on. But the identities of those who fall into these categories may change: the set of "my friends" includes different people at different times. What makes them my friends depends primarily on who they are, not who they have been. Indeed, my affective concern for them depends on features of them that affect our relationship (where these features may also include our shared history). To the extent I want to reidentify one of them, then, this often involves establishing or ensuring that they have the same relation to me now that grounded my affective concern in the past. Depending on the nature of our friendship, then (i.e. what it is that warrants my affective concern), the relevant ownership relation may be delivered by (a) psychological continuity on their part, (b) one aspect of psychological continuity (perhaps just continuity of character, or persistence of beliefs/desires/goals), (c) some combination of physical and psychological continuity, or (d) mere physical continuity (for those who are seriously shallow). And while all of these may still fall under the general rubric of human identity, that characterization completely glosses over what is fascinatingly different about each, marking very different construals of both friendship and ownership.

${ }^{34}$ Nor was it meant to.

${ }^{35}$ I'm unsure psychological continuity is even what matters in survival, but this is a story for another day. 
different relations, and furthermore it is doubtful that for any of these concerns psychological continuity/connectedness is actually what matters. Instead, sometimes there are subsets of the psychological relations making up continuity/connectedness that are relevant, sometimes it is mere physical continuity that matters, and sometimes all that matters is my current relation to some other person (so continuity of any sort is irrelevant). What this suggests, then, is that, not only does identity not matter for our practical concerns, but also the relation Parfit thought mattered in identity is irrelevant to our practical concerns. So perhaps what I am advocating should be labeled the "Identity Really Doesn't Matter" view.

The second surface similarity my view bears is to an aspect of Schechtman's position in her early book The Constitution of Selves. There she makes an important distinction between two different questions identity theorists might pursue. The first is the reidentifcation question: what makes $\mathrm{X}$ at $\mathrm{t} 1$ identical to $\mathrm{Y}$ at $\mathrm{t} 2$ ? The second is the characterization question: what makes various thoughts, experiences, actions, and events properly attributable to some agent (Schechtman 1996: e.g. 73)? Pursuit of the latter question involves pursuit of identity of a different sort, she thinks, having to do with the sense relevant to an "identity crisis," according to which the identity discovered will consist in "the set of characteristics that make a person who she is" (Schechtman 1996: 76). For Schechtman, the best unifying account of this sort appeals to narrative: what makes these various characteristics properly attributable to me is their being incorporated into the self-told story of my life (Schechtman 1996: ch. 5).

I take myself in part to be reminding us of the importance of the characterization question. The relation on which our various practical concerns are grounded is not numerical identity but is instead what I have referred to as the ownership relation. The relevant question then becomes what such ownership — characterization-consists in. And this is where I depart significantly from Schechtman. Whereas early-Schechtman believes that our various practical concerns are unified via narrative identity, and laterSchechtman believes (in addition?) that our various practical concerns are unified in targeting person-lives, I believe that the practical concerns just aren't unified, that what each of their relevant ownership relations consist in are simply different. I advocate pluralism regarding our person-related practical concerns in virtue of their plural grounds. ${ }^{36}$ To force a unity upon this set under some umbrella rubric is to overlook precisely those fascinating and important pluralities, and it also may run headlong into contradiction (where, as in the compensation example, the benefited agent both is and is not identical to the burdened agent). So while my view is distinguished from Parfit's in denying the importance of what ostensibly matters in numerical identity (which addresses the reidentification question), it is also distinguished from Schechtman's in denying the importance of narrative or person-life identity as providing a unified answer to the characterization question. Perhaps, then, mine should be labeled the "Identity Really Really Doesn't Matter View."

\footnotetext{
${ }^{36}$ See Schechtman's discussion of an earlier sketch of my position in her 2014: 82-8.
} 
I close by returning to the epigraphs. Contrary to John Merrick's animated cry he is-we all are-animals. But beyond the Animals' song, we are also human beings. And we are also persons (to translate Merrick's "man"). To the extent there are characteristics specific to each, we own them in that specific capacity. ${ }^{37}$ As an animal, I have "breath, flesh, flesh and blood, physique, strength, power, vigor, force, spring, elasticity, tone, and grace." As a human being, I participate in a way of life giving rise to various sorts of self-referential concerns, friendships, and views of others generally that are expressed in uniquely human ways. As a person, I am a self-conscious moral agent producing actions and attitudes that are properly attributable to me for purposes of responsibility. Our practical concerns are distributed across these categories, some of them attached to our animality, some of them attached to our humanity, and some of them attached to our personhood. And while most (all?) of the concerns in the set do at least track what is ours, the conditions of said ownership are different enough in each case to thwart genuine unity in anything but name. Animalism indeed does poorly in accounting for our practical concerns, but then again, so does any theory of personal or human identity, or, for that matter, any theory purporting to account for the set as a whole. Revealing the thoroughgoing pluralism of our practical concerns should finally expose the sham that their marriage to identity has always really been. ${ }^{38}$

\section{References}

Buchanan, Allen. 1988. "Advance Directives and the Personal Identity Problem." Philosophy and Public Affairs 17: 277-302.

DeGrazia, David. 2005. Human Identity and Bioethics (Cambridge: Cambridge University Press).

Frankfurt, Harry. 1988. The Importance of What We Care About (Cambridge: Cambridge University Press).

Jeske, Diane. 1993. "Persons, Compensation, and Utilitarianism." The Philosophical Review 102: 541-75.

Johnston, Mark. 1997. “Human Concerns Without Superlative Selves.” In Jonathan Dancy, ed., Reading Parfit (Oxford: Blackwell Publishers), 149-79.

Lewis, David. 1976. "Survival and Identity." In Amelie Oksenberg Rorty, ed., The Identities of Persons (Berkeley: University of California Press), 17-40.

Locke, John. 1975. "Of Identity and Diversity." In John Perry, ed., Personal Identity (Berkeley: University of California Press), 33-52.

Martin, Raymond. 1998. Self-Concern (Cambridge: Cambridge University Press).

${ }^{37}$ Are we essentially one or the other? This is irrelevant to the question of ownership, it seems. I may own something qua any variety of phase sortals.

38 This chapter was a long time coming out, and I've learned a lot from many people about the relevant issues over the years. For feedback on various drafts and presentations of the material, I'm grateful to Stephan Blatti, Victor Kumar, Shaun Nichols, Eric Olson, Marya Schechtman, David Silver, and Hannah Tierney. I am also grateful for helpful discussion of some of the material herein with the participants in my seminars on Personal Identity and Ethics at Bowling Green State University in 2011, and Tulane in 2011 and 2015, as well as the audiences at my presentation of this material at Ohio State and the University of Arizona. 
Olson, Eric. 1997. The Human Animal (Oxford: Oxford University Press).

Parfit, Derek. 1984. Reasons and Persons (Oxford: Oxford University Press).

Schechtman, Marya. 1996. The Constitution of Selves (Ithaca, NY: Cornell University Press).

Schechtman, Marya. 2010. "Personhood and the Practical." Theoretical Medicine and Bioethics 31: 271-83.

Schechtman, Marya. 2014. Staying Alive: Personal Identity, Practical Concerns, and the Unity of a Life. Oxford: Oxford University Press.

Shoemaker, David W. 2007. "Personal Identity and Practical Concerns." Mind 116: 317-57.

Shoemaker, David W. 2010. "The Insignificance of Personal Identity for Bioethics." Bioethics 24: 481-9.

Shoemaker, David W. 2011a. "Moral Responsibility and the Self." In Shaun Gallagher, ed., Oxford Handbook of the Self (Oxford: Oxford University Press), 487-520.

Shoemaker, David W. 2011b. "Responsibility Without Identity." Harvard Review of Philosophy 18: 109-32.

Sider, Theodore. 2001. Four-Dimensionalism (Oxford: Oxford University Press). 
